\title{
Fracture and Delamination of Chromium Thin Films on Polymer Substrates
}

\author{
M.J. CORDILL, A. TAYLOR, J. SCHALKO, and G. DEHM
}

\begin{abstract}
New emerging technologies in the field of flexible electronic devices require that metal films adhere well and flex with polymer substrates. Common thin film materials used for these applications include copper $(\mathrm{Cu})$ with an adhesion interlayer of chromium $(\mathrm{Cr})$. Copper can be quite ductile and easily move with the polymer substrate. However, $\mathrm{Cr}$ is more brittle and fractures at lower strains than $\mathrm{Cu}$. This study aims to examine the fracture and subsequent buckling and delamination of strained $\mathrm{Cr}$ films on polyimide (PI). In-situ scanning electron microscope (SEM) straining is used to systematically study the influence of film thickness on fracture and buckling strains. Film fracture and delamination depend on film thickness, and increases in crack and buckle density with decreasing thickness are explored by a shear lag model.
\end{abstract}

DOI: $10.1007 / \mathrm{s} 11661-009-9988-9$

(C) The Minerals, Metals \& Materials Society and ASM International 2009

\section{INTRODUCTION}

OvER the past few years, metal and ceramic films on polymer substrates have led to the emergence of deformable electronics, such as foldable displays, sensor skins, and electronic textiles. The typical route to create deformable devices on polymer substrates is to fabricate stiff islands, commonly made with silicon-nitride, where active cells (thin film transistors) are fabricated and connected by metal lines. ${ }^{[1-4]}$ These interconnect lines must deform with the substrate and survive strains greater than 10 pct while maintaining electrical conductivity. ${ }^{[1,2,5]}$ Several studies have examined the tensile strength of blanket copper $(\mathrm{Cu})$, aluminum, and gold films on polymer substrates ${ }^{[6-11]}$ as well as gold lines. ${ }^{[4,12]}$ Further research on ceramic coatings on polymers for barrier gas coatings has also been completed. ${ }^{[13-15]}$ Compared to bulk metals, these films on polymer substrates can have small rupture strains (less than 2 pct) but high strengths; ${ }^{[7,16]}$ however, when the film is well bonded to the substrate, it will have high rupture strains due to the lack of localized deformation that is

M.J. CORDILL, Postdoctoral Researcher, A. TAYLOR, Ph.D. Candidate, and G. DEHM, Professor and Head, are with the Erich Schmid Institute of Materials Science of the Austrian Academy of Sciences and the Department of Materials Physics at the University of Leoben, Jahnstrasse 12, A-8700, Leoben, Austria. Contact e-mail: megan.cordill@oeaw.ac.at J. SCHALKO is with the Research Unit for Integrated Sensor Systems of the Austrian Academy of Sciences, Viktor Kaplan Strasse 2, A-2700 Wiener Neustadt, Austria.

This article is based on a presentation given in the symposium entitled "Mechanical Behavior of Nanostructured Materials," which occurred during the TMS Spring Meeting in San Francisco, CA, February 15-19, 2009, under the auspices of TMS, the TMS Electronic, Magnetic, and Photonic Materials Division, the TMS Materials Processing and Manufacturing Division, the TMS Structural Materials Division, the TMS Nanomechanical Materials Behavior Committee, the TMS Chemistry and Physics of Materials Committee, and the TMS/ASM Mechanical Behavior of Materials Committee.

Article published online September 23, 2009 suppressed by the strong adhesion. ${ }^{[3]}$ When the film is brittle like silicon nitride, no plastic elongation takes place and fracture is caused by the breaking of an array of atomic bonds. ${ }^{[1]}$ Failure of the films by cleavage fracture is similar to previous studies of ceramic films on metal substrates pulled in tension. ${ }^{[17-19]}$

With the periodic cracking method that is based on a shear lag analysis, ${ }^{[17,18,20,21]}$ the maximum shear traction that is supported by the interface can be calculated. The periodic cracking method was first developed to study the shear properties of metal-ceramic interfaces, ${ }^{[17]}$ with similar periodic cracking of other material systems having also been studied. ${ }^{[22-25]}$ With the metal-ceramic system, plastic deformation in the metal substrate is accommodated by elastic deformation of the ceramic film until the fracture stress is reached. With metalpolymer interfaces, the plastic deformation of the metal is accommodated by the elastic deformation of the polymer substrates until the fracture stress of the metal film is reached. At fracture, the in-plane traction in the film is transferred as shear traction to the interface adjacent to the free edge of the crack. The shortest distance between cracks is the characteristic relaxation distance of the shear traction. This leads to defining the maximum shear traction supported by the interface, $\tau_{\max }$, as a function of the fracture stress of the film, $\sigma_{\text {frac }}$, as

$$
\tau_{\max }=\frac{3}{4} \pi \frac{h}{\lambda} \sigma_{\text {frac }}
$$

where $h$ is the film thickness and $\lambda$ is the mean spacing between cracks. The fracture stress can be estimated with Eq. [2], assuming that the film behaves elastically,

$$
\sigma_{\mathrm{frac}} \approx E_{f} \varepsilon_{\mathrm{frac}}
$$

where $E_{f}$ is the elastic modulus of the film and $\varepsilon_{\text {frac }}$ is the fracture strain. It should be noted that Eq. [2] does not take into account the residual in-plane stress of the film 
after deposition. It is easily included, as shown by Andersons and Leterrier et al. ${ }^{[13-15]}$ Similar shear lag analyses have been performed with $\mathrm{SiO}_{2}$-PET film systems as well as $\mathrm{SiN}_{x}$-Kapton film systems. ${ }^{[13-15]}$ However, some differences are found between the preceding approach and others, ${ }^{[17,18]}$ but both are based on the shear lag analysis of Kelly and Tyson. ${ }^{[26]}$

In-situ tensile tests performed inside a scanning electron microscope (SEM) allow one to determine the system's fracture strain, where cracks first initiate, as well as any subsequent buckling and delamination that may occur. ${ }^{[19]}$ This type of experiment can provide a wealth of information that can be used to improve existing adhesion and deformation models currently being implemented ${ }^{[1,27]}$ to predict material failure and lifetimes of the material systems. Current thin film systems being examined for the connecting lines of flexible devices include $\mathrm{Cu}$ or $\mathrm{Au}$ with an adhesion layer of chromium $(\mathrm{Cr})$. It has been well known that $\mathrm{Cr}$ can increase the adhesion energy of metal films on polymer substrates, for example, $\mathrm{Cu}$ on $\mathrm{PI}^{[27]}$ and $\mathrm{Au}$ on PDMS. ${ }^{[13]}$ It has also been observed that $\mathrm{Cr}$ adhesion layers (10 to $20 \mathrm{~nm}$ in thickness) will fracture before cracks are viewed in the overlying $\mathrm{Cu}$ films, and the failure occurs via channel cracking perpendicular to the tensile loading direction. ${ }^{[24]}$ This study aims to examine the fracture behavior of bare $\mathrm{Cr}$ films on PI substrates to better understand the mechanisms that lead to failure of this adhesion layer. Of importance is whether fracture strain is influenced by the film thickness.

\section{EXPERIMENTAL PROCEDURE}

Chromium films were deposited onto cleaned 50- $\mu \mathrm{m}-$ thick UPLIEX brand PI films $(E=8.5 \mathrm{GPa})$. The PI film was cleaned by soaking it in a 10 pct aqueous solution of RBS 50 (a laboratory cleaning concentrate with high $\mathrm{pH}$ ) for 24 hours at room temperature, followed by a deionized water rinse and a $1 \mathrm{MHz}$ ultrasonic cleaning process. The $\mathrm{Cr}$ layers were deposited by e-beam evaporation in a Balzers BAK 550 evaporation machine with the vacuum at $2.10 \times$ $10^{-7}$ mbar and using a deposition rate of $0.5 \mathrm{~nm} / \mathrm{s}$. Four film thicknesses were made and studied: 50, 100, 200 , and $500 \mathrm{~nm}$. It is known that adhesion layers are commonly $50 \mathrm{~nm}$ or less; however, in order to fully study the failure mechanism, an order of magnitude of film thickness was used. The 100-, 200-, and 500-nm films have residual tensile stresses on the order of $1 \mathrm{GPa}$ (1.2, 1, and $0.8 \mathrm{GPa}$, for the 100, 200, and $500 \mathrm{~nm}$, respectively), as determined by X-ray diffraction using the $\sin ^{2} \Psi$ method. The same method was also used on the 50-nm film but was unsuccessful in measuring a stress because the film was too thin to get a reliable peak shift. In the analysis, a 1-GPa residual stress is assumed for the $50-\mathrm{nm}$ film. Tensile cracks formed before straining experiments of the 200- and 500-nm films.

The structure of the films was determined with electron microscopy techniques. By careful sample preparation, cross-sectional transmission electron microscopy (TEM) images and diffraction patterns of the 50- and 500-nm films were taken. Figure 1 shows a columnar grain structure with peculiar peaks for both film thicknesses. The peaks are also visible in scanning electron microscopy images of the film surfaces (not shown). Diffraction patterns indicate that the films are polycrystalline. The average grain size of the films is on the order of $50 \mathrm{~nm}$ for all film thicknesses.

The films were pulled in tension using a small scale tensile device (Kammrath and Weiss, Dortmund, Germany) that has a maximum displacement of $6 \mathrm{~mm}$. The sample geometry used was approximately $1-\mathrm{cm}$ wide with a $3-\mathrm{cm}$ gage length. Each test was carried out using a $10-\mu \mathrm{m} / \mathrm{s}$ displacement rate. The tensile device was used to perform both ex-situ and in-situ tests inside the SEM. In-situ tests were initially stopped every 100 $\mu \mathrm{m}$ of displacement until the first cracks perpendicular to the tensile direction were observed (approximately $600-\mu \mathrm{m}$ total displacement) in order for SEM images to be taken of the samples at various magnifications. After the first $600 \mu \mathrm{m}$ of displacement, the experiment was stopped every $200 \mu \mathrm{m}$ of displacement. The images were then correlated to the strain. Comparisons of ex-situ and in-situ tests indicate that the electron beam and the vacuum do not alter the results notably.
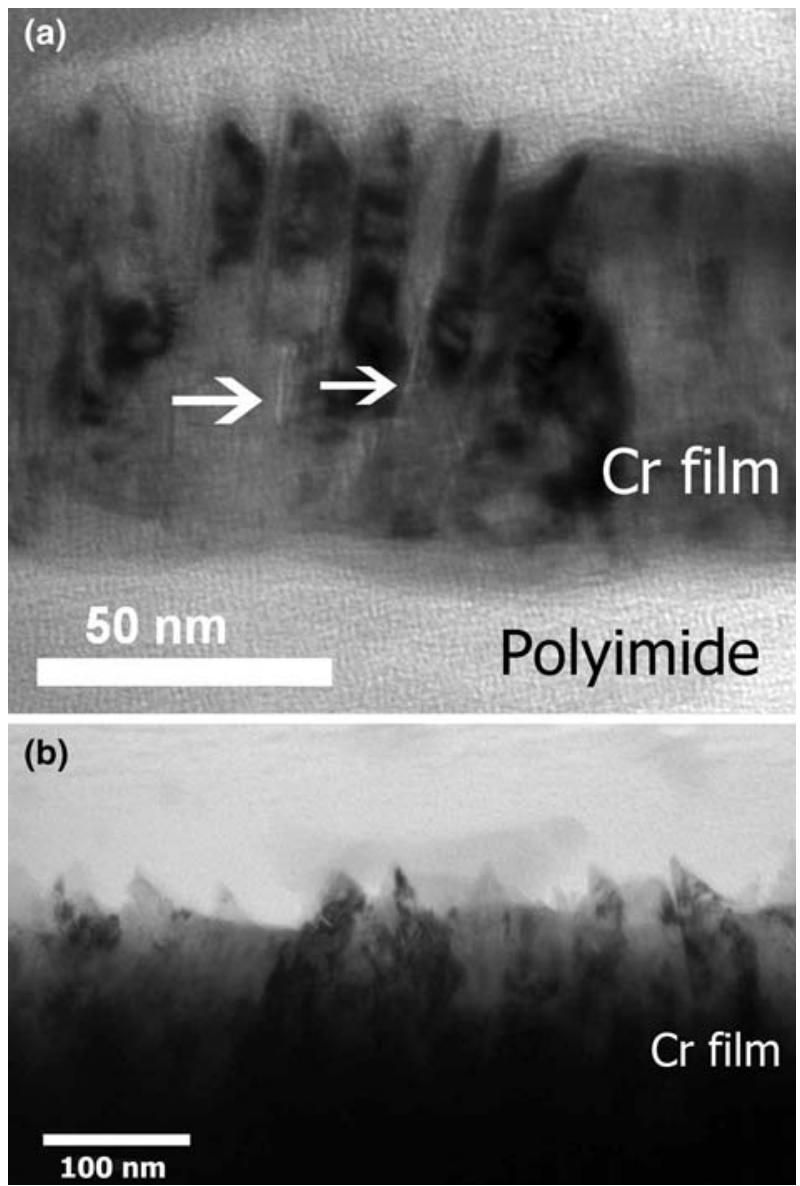

Fig. 1-Bright-field TEM images of the (a) 50- and (b) 500-nm-thick films. The arrows in (a) indicate regions of possible columnar porosity. 


\section{RESULTS AND DISCUSSION}

The load vs strain behavior of the Cr films on PI is shown in Figure 2(a) for ex-situ experiments. Both ex-situ and in-situ experiments illustrate that there is no pronounced thickness dependence on the load and strain response. This may be explained by the small grain size of $50 \mathrm{~nm}$, which is for all thicknesses the smallest dimension and thus expected to control the mechanical response of the films. ${ }^{[2]}$ The ex-situ samples were all strained to $11 \mathrm{pct}$, while in-situ tests were performed to 12 to 18 pet strain. With the in-situ experiments, cracks perpendicular to the loading direction were observed to initiate at less than $1 \mathrm{pct}$ strain for all thicknesses (Table I). Measured crack densities increase with decreasing film thickness (Figure 2(b)). The crack density of the thickest film $(500 \mathrm{~nm})$ reaches a steady state at about 4 pet strain, which is at a lower strain value than the thinner films. The 100- and 200-nm films reach a steady state at approximately 5 pct strain. Figure 3 illustrates the cracking found in all four thicknesses at 11 pct strain. Crack density as a function of strain of the films $100 \mathrm{~nm}$ and greater reaches a clear plateau in the data indicating the steady state. The thinnest film, $50 \mathrm{~nm}$, does not reach such a plateau within the prescribed straining limit of the apparatus. Rather, a change in slope is reached at about 7 pct strain and then continues to gradually increase, up to 18 pct global strain. This indicates that cracks are still forming in the very thin brittle films where cracks stop forming in the thicker films. The continued crack growth could be of significance and may aid in increasing the strain a system can withstand. The average crack spacing at saturation can also be found in Table I.

Due to the fact that the fracture strains of the films can be observed with the in-situ experiments, it is easy to calculate the maximum shear stress of the interface, $\tau_{\max }$, assuming that the fracture stress can be estimated based on Eq. [2] with an elastic modulus of $280 \mathrm{GPa}$. Since the grain size is homogenous for the various film thicknesses and too small to allow considerable plasticity, this approximation is justified. There is a wide distribution of observed fracture strains but a trend of decreasing fracture strain with increasing film thickness is found, as shown in Table I. The fracture strain is defined when the first new cracks perpendicular to the tensile direction are observed with the SEM during the in-situ experiment. Using Eq. [1] and the fracture stress values from Eq. [2], the maximum shear stress of the interface also decreases with increasing film thickness, as shown in Table I. The calculated values for the Cr-PI system are lower (119 to $31 \mathrm{MPa}$ ) than that of a metalceramic interface $\left(1.7 \mathrm{GPa}\right.$ for $\mathrm{Cu}-\mathrm{SiO}_{2}{ }^{[14]}$ and 0.4 to $0.8 \mathrm{GPa}$ for $\mathrm{Cu}-\mathrm{Al}_{2} \mathrm{O}_{3}{ }^{[28]}$ ), but the values are reasonable. It should be noted that the residual stresses in the thicker films $(>100 \mathrm{~nm}$ ) have not been considered with this model. Rather, the formation of new cracks due to the tensile loading is considered to be the over-riding mechanism. When the residual stress of about $1 \mathrm{GPa}$ of the films is included in the analysis, the fracture stresses range between 3.1 and $1.2 \mathrm{GPa}$ and the maximum interface shear strength values increase to 175 to

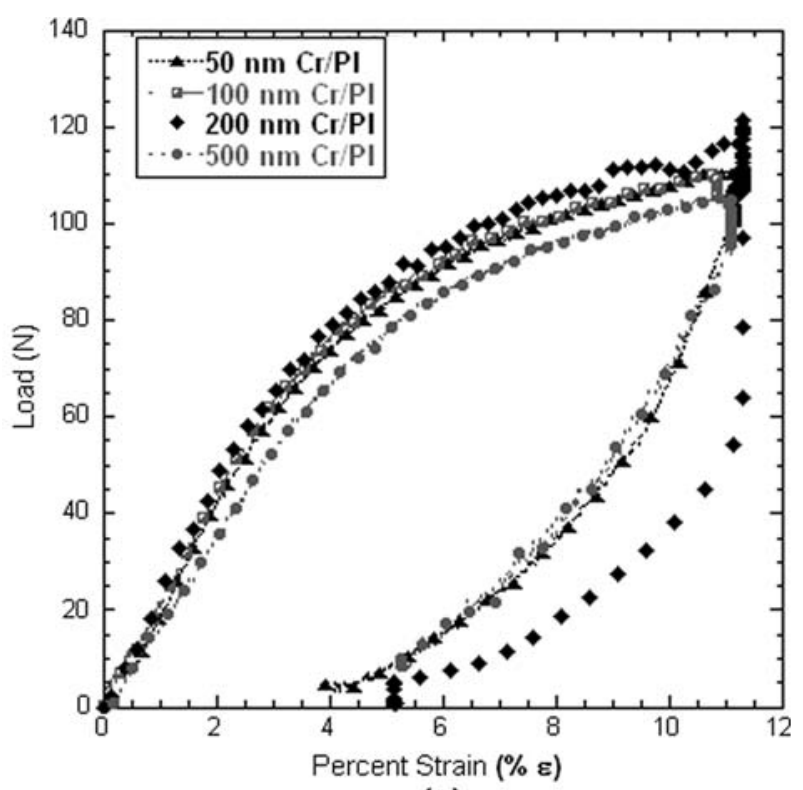

(a)

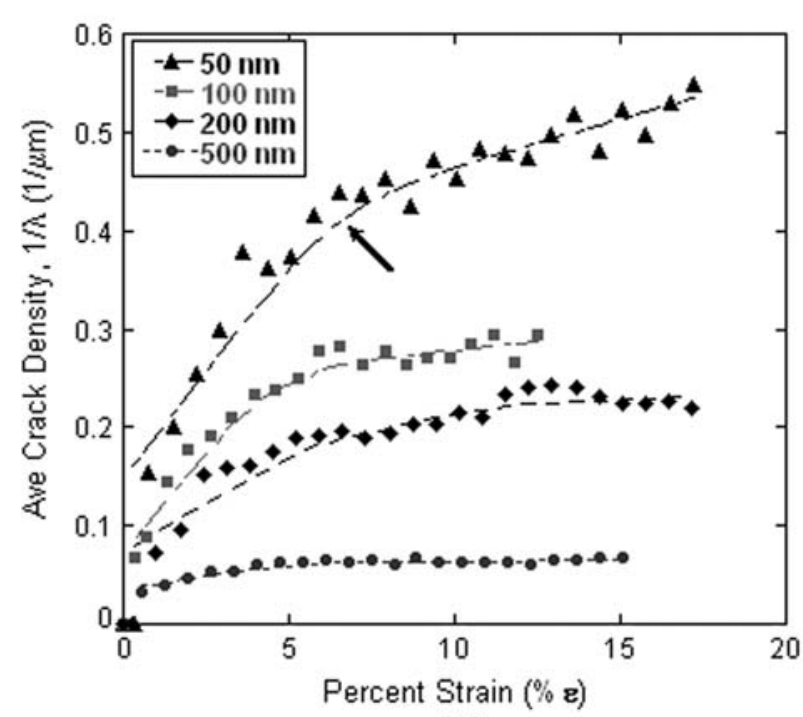

(b)

Fig. 2-(a) Load vs strain response of the four Cr film thicknesses on PI. (b) Crack density as a function of strain for all four Cr thicknesses. Each thickness reaches the steady-state region at a different strain ranging between 4 and 7 pct. The 50 -nm-thick film, however, does not quite reach a steady state. Rather, the slope of the data changes (arrow) at about 7 pct.

$93 \mathrm{MPa}$, respectively, for the 50- to 500-nm film. These values are shown in brackets (i.e., [175]) in Table I. In either case, the data show a tendency for the thinner films to have higher interfacial shear strengths, which is most likely caused by the decrease in fracture stress due to a scaling with the film thickness because the grain size is constant for all thicknesses. A possible explanation could be the presence of columnar porosity, ${ }^{[29,30]} \mathrm{com}-$ monly observed with columnar grained films. This type of defect may be present in these films, as shown in Figure 1(a) (arrows) at the column boundaries. Further TEM examination is required in order to say with 
Table I. Measured and Calculated Values of Fracture Strain and Stress, Average Crack and Buckle Spacing, and Maximum Interface Shear Strength for All Performed In-Situ Experiments; Values that Include the Residual Tensile Stress of 1 GPa are Shown in Brackets

\begin{tabular}{|c|c|c|c|c|c|c|}
\hline Film Thickness & $\begin{array}{l}\text { Pct Fracture } \\
\text { Strain }\end{array}$ & $\begin{array}{c}\text { Fracture } \\
\text { Stress }(\mathrm{GPa})\end{array}$ & $\begin{array}{l}\text { Average Crack } \\
\text { Spacing }(\mu \mathrm{m})\end{array}$ & $\begin{array}{l}\text { Maximum Interface } \\
\text { Shear Strength (MPa) }\end{array}$ & $\begin{array}{l}\text { Pct Buckle } \\
\text { Strain }\end{array}$ & $\begin{array}{c}\text { Average Buckle } \\
\text { Spacing }(\mu \mathrm{m})\end{array}$ \\
\hline \multirow[t]{2}{*}{$50 \mathrm{~nm}$} & 0.58 & $1.6[2.6]^{*}$ & $1.9 \pm 0.1$ & $100[163]^{*}$ & 8 & \multirow[t]{2}{*}{$4.4 \pm 1.5$} \\
\hline & 0.76 & $2.1[3.1]^{*}$ & $2.1 \pm 0.2$ & 119 [175]* & 13 & \\
\hline $100 \mathrm{~nm}$ & 0.32 & $0.9[2.1]$ & $4.1 \pm 0.5$ & 52 [120] & 13 & $11 \pm 6$ \\
\hline $200 \mathrm{~nm}$ & 0.23 & 0.64 [1.6] & $4.8 \pm 0.4$ & 64 [161] & 17 & $12 \pm 5.9$ \\
\hline \multirow[t]{2}{*}{$500 \mathrm{~nm}$} & 0.15 & $0.42[1.2]$ & $15.5 \pm 0.5$ & 31 [93] & 10 & \multirow[t]{2}{*}{$62 \pm 35$} \\
\hline & 0.19 & 0.54 [1.3] & $16.7 \pm 1$ & 38 [94] & 10 & \\
\hline
\end{tabular}

*The residual stress of the 50-nm film could not be measured and was assumed to be 1 GPa and was based on the stress results of the other films.

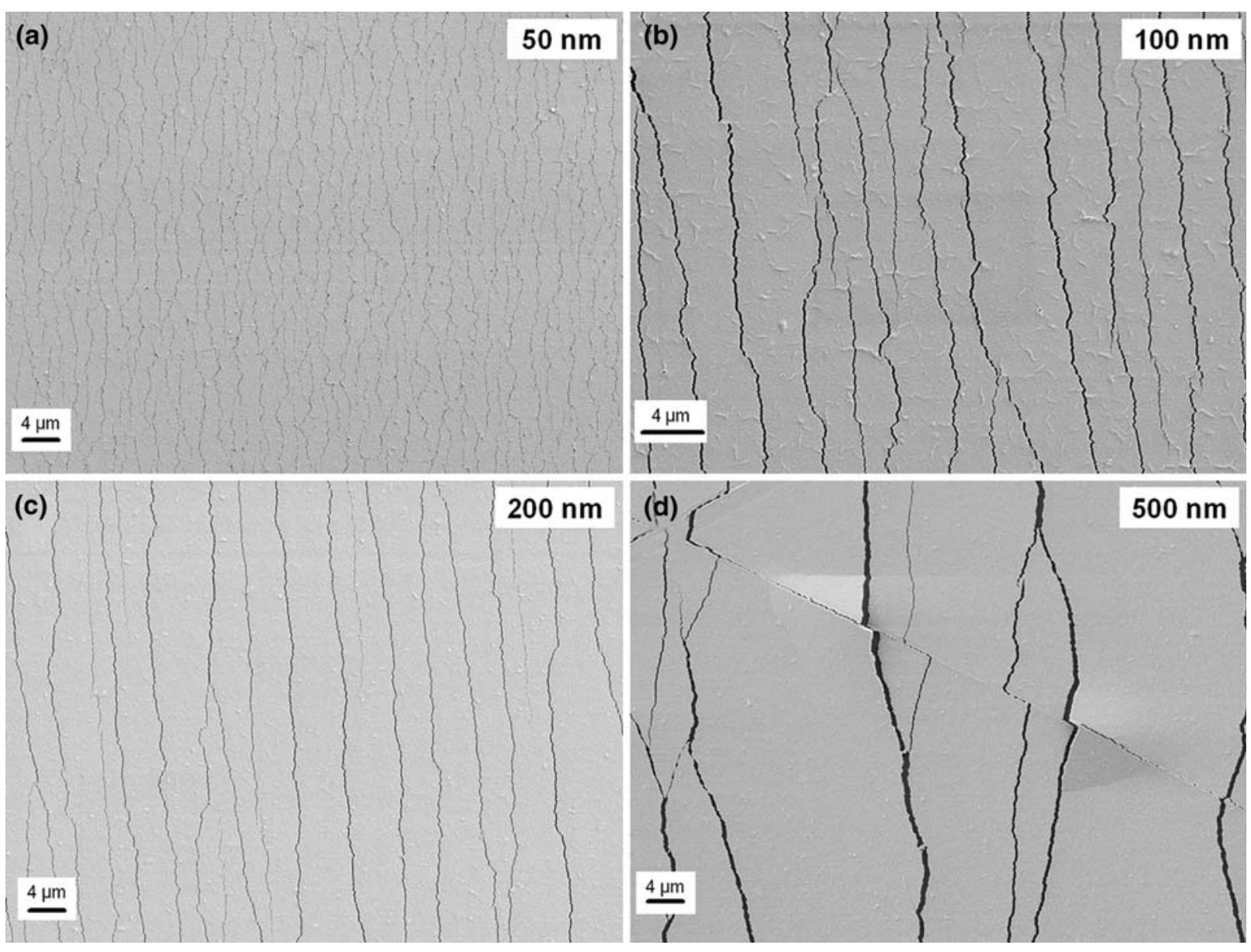

Fig. 3-The SEM micrographs at the same magnification of all four films strained to 12 pct. The effect that thickness has on crack spacing is evident as well as the first stages of buckling in the 500-nm film. (a) 50-nm, (b) 100-nm, (c) 200-nm, and (d) 500-nm.

certainty how columnar porosity should be taken into account. Larger defects in the thicker films, e.g., cracks caused by residual stresses from deposition, will cause a lower fracture stress and as a consequence the simple model provides only an upper limit of the interfacial shear strength. However, the large crack density and lack of a steady-state regime may be a cause for overlayers of $\mathrm{Cu}$ or gold to fail.

Increasing the strain of the film system leads to delamination and buckling at the interface. Buckling is caused by the lateral compressive deformation of the film on the substrate due to the different Poisson's ratios of $\mathrm{Cr}$ and PI (0.21 and 0.3, respectively). This occurs above $\sim 10$ pet strain along the tensile direction, with the exact amount of strain depending on the film thickness. The nature of the buckling is also dependent on film thickness. With the 500-nm film, buckles form with a crack at the apex and at the edges of the buckle, forming a triangle buckle, which can lead to immediate spalling of the film. On the other hand, the $50-\mathrm{nm}$ film 

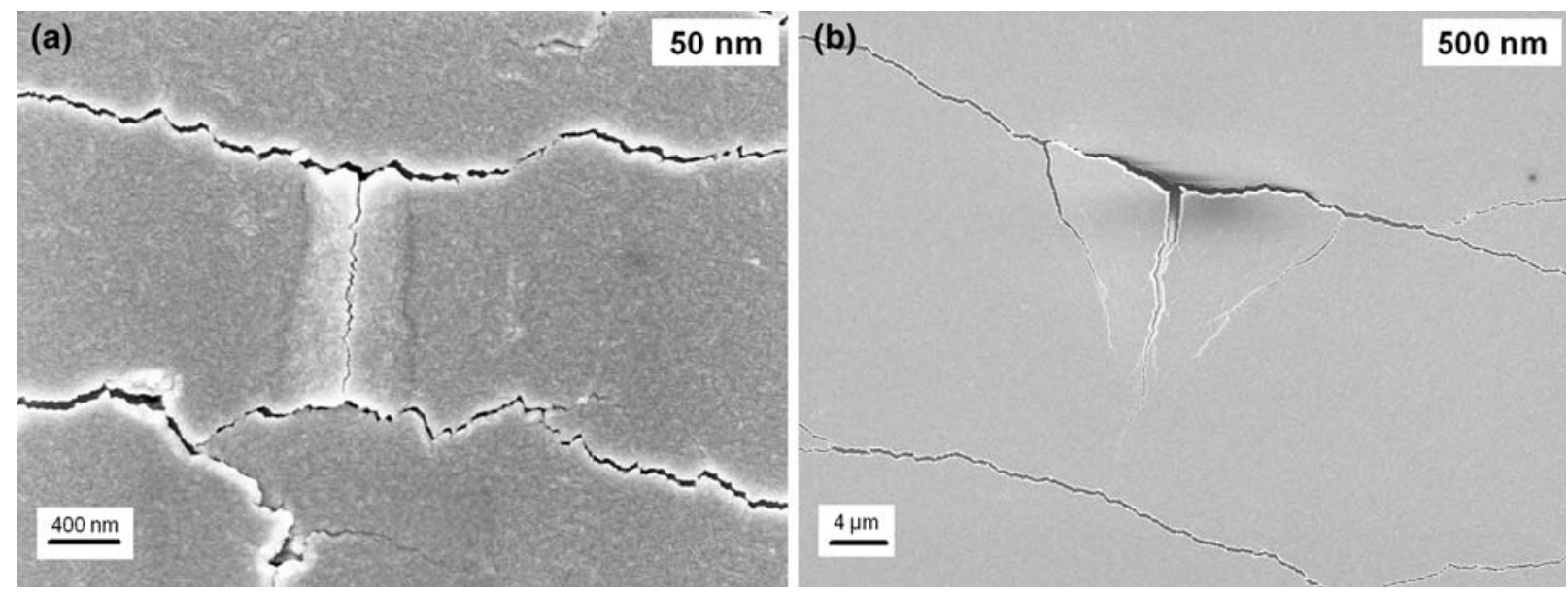

Fig. 4-SEM images of buckles found on the (a) 50- and the (b) 500-nm films.

buckles are much smaller and form straight buckles between the initial cracks with a cracked apex as well. Figure 4 shows examples of the buckling with the two film thicknesses. Inspection of the buckling behavior may be a way to determine the work of separation of the film system. Further experiments combined with modeling are currently under way to examine this behavior.

\section{CONCLUSIONS}

The failure of blanket chromium films commonly used as adhesion layers to increase the interfacial strength of metal-polymer film systems has been investigated. Under tension, $\mathrm{Cr}$ films fracture and delaminate from the PI substrate with a brittle cleavage fracture behavior. Initial crack formation perpendicular to the loading direction occurs at strains less than 1 pct, much lower than the fracture strain of the $\mathrm{Cu}$ films whose adhesion is being improved in applications. The cracking behavior can be compared to ceramic films on metal substrates pulled in tension, and a periodic cracking model for calculating the maximum interface shear strength was used. The average interface shear strength is $67 \pm 35 \mathrm{MPa}$. The spacing of the cracks reaches a steady state at approximately 4 to 5 pct strain for thick films $(\geq 100 \mathrm{~nm})$. For 50 -nm-thick films, the crack density does not reach a steady-state region even after 18 pct global strain has been induced. Crack and buckle spacings also increase with increasing film thickness, with buckles occurring at 8 to 17 pet strain depending on film thickness. These buckles can be used to measure adhesion energies by taking the shape and possible cracks of the buckles into account. This study has shown that thin adhesion interlayers continue to form cracks during tensile deformation up to high strains. The continued fracture process and large crack density may cause metal bilayer systems on polymers (e.g., $\mathrm{Cu}$ film on $\mathrm{Cr}$ adhesion layer) to be less reliable than a thicker adhesion layer with a lower crack density.

\section{ACKNOWLEDGMENTS}

Funding for this research has been provided by the FWF Lise Meitner fellowship (Grant No. M1041N14). P. Svasek, Research Unit for Integrated Sensor Systems, Austrian Academy of Sciences (Vienna), is acknowledged for sample preparation help. R. Raj and F.D. Fischer are gratefully acknowledged for helpful discussions. K. Martinschitz and J. Keckes, Materials Physics Department, University of Leoben, are also acknowledged for help with the XRD analysis.

\section{REFERENCES}

1. T. Li, Z.Y. Huang, Z.C. Xi, S.P. Lacour, S. Wagner, and Z. Suo: Mech. Mater., 2005, vol. 37, pp. 261-73.

2. S.P. Lacour, C. Tsay, and S. Wagner: IEEE Electron Dev. Lett., 2004, vol. 25, pp. 792-94.

3. Y. Xiang, T. Li, Z. Suo, and J. Vlassak: Appl. Phys. Lett., 2005, vol. 87, pp. 161910-1-161910-3.

4. S.P. Lacour, S. Wagner, R.J. Narayan, L. Teng, and Z. Suo: J. Appl. Phys., 2006, vol. 100, pp. 014913-1-014913-3.

5. S.P. Lacour, J. Jones, S. Wagner, L. Teng, and S. Zhigang: Proc. IEEE, 2005, vol. 93, pp. 1459-67.

6. O. Kraft, M. Hommel, and E. Arzt: Mater. Sci. Eng. A, 2000, vol. 88 , pp. $209-16$

7. D.Y.W. Yu and F. Spaepen: J. Appl. Phys., 2004, vol. 95, pp. 2991-97.

8. P.O. Renault, P. Villian, C. Coupeau, P. Goudeau, and K.F. Badawi: Thin Solid Films, 2003, vol. 424, pp. 267-73.

9. S.H. Oh, M. Legros, D. Kiener, P. Gruber, and G. Dehm: Acta Mater., 2007, vol. 55, pp. 5558-71.

10. G. Dehm, S.H. Oh, P. Gruber, M. Legros, and F.D. Fischer: Acta Mater., 2007, vol. 55, pp. 6659-65.

11. P.A. Gruber, J. Bohm, F. Onuseit, A. Wanner, R. Spolenak, and E. Arzt: Acta Mater., 2008, vol. 56, pp. 2318-35.

12. S. Olliges, P.A. Gruber, S. Orso, V. Auzelyte, Y. Ekinci, H.H. Solak, and R. Spolenak: Scripta Mater., 2008, vol. 58, pp. $175-78$.

13. J. Andersons, Y. Leterrier, G. Tornare, P. Dumont, and J.-A.E. Manson: Mech. Mater., 2007, vol. 39, pp. 834-44.

14. Y. Leterrier: Prog. Mater. Sci., 2003, vol. 48, pp. 1-55.

15. Y. Leterrier, J. Andersons, Y. Pitton, and J.-A.E. Manson: J. Polym. Sci. B, 1998, vol. 35, pp. 1463-72.

16. S.P. Lacour, S. Wagner, H. Zhenyu, and Z. Suo: Appl. Phys. Lett., 2003, vol. 82, pp. 2404-06. 
17. D.C. Agrawal and R. Raj: Acta Metall., 1989, vol. 37, pp. 1265-70.

18. V.C. Jobin, R. Raj, and S.L. Phoenix: Acta Metall. Mater., 1992 vol. 40, pp. 2269-80.

19. G. Rochat, Y. Leterrier, P. Fayet, and J.-A.E. Manson: Thin Solid Films, 2003, vol. 437, pp. 204-10.

20. G. Singh, Y. Yu, F. Ernst, and R. Raj: Acta Mater., 2007, vol. 55, pp. 3049-57.

21. M.D. Thouless, E. Olsson, and A. Gupta: Acta Metall. Mater. 1992, vol. 40, pp. 1287-92.

22. Z.C. Xia and J.W. Hutchinson: J. Mech. Phys. Solids, 2000, vol. 48, pp. 1107-31

23. M.S. Hu and A.G. Evans: Acta Metall., 1989, vol. 37, pp. 917-25.

24. Z. Suo: in Comprehensive Structural Integrity, I. Milne, R.O. Ritichie, and B. Karihaloo, eds., Elsevier, Amsterdam, 2003, vol. 8, pp. 265-324.
25. J.W. Hutchinson and Z. Suo: Adv. Appl. Mech., 1992, vol. 29, pp. 63-191.

26. A. Kelly and W.R. Tyson: J. Mech. Phys. Solids, 1965, vol. 13, pp. 329-50.

27. N. Lu, X. Wang, Z. Suo, and J. Vlassak: Appl. Phys. Lett., 2007, vol. 91, pp. 221909-1-221909-3

28. G. Dehm, M. Ruhle, H.D. Conway, and R. Raj: Acta Mater., 1997, vol. 45, pp. 489-99.

29. A. Misra and M. Nastasi: J. Mater. Res., 1999, vol. 14, pp. 446669.

30. A. Misra and M. Nastasi: Appl. Phys. Lett., 1999, vol. 75, pp. 3123-25. 